\title{
Phylogenies of atpD and recA support the small subunit rRNA-based classification of rhizobia
}

Department of Biology, University of York, PO Box 373, York YO10 5YW, UK

\author{
M. W. Gaunt,† S. L. Turner, $\ddagger$ L. Rigottier-Gois, § S. A. Lloyd-Macgilp\| \\ and J. P. W. Young
}

Author for correspondence: J. P. W. Young. Tel: +44 1904 432914. Fax: +44 1904432860. e-mail: jpy1@york.ac.uk

Keywords: Rhizobium, Sinorhizobium, Mesorhizobium, recA, atpD

\section{INTRODUCTION}

The rhizobia are root-nodulating bacteria responsible for a significant part of the global fixation of nitrogen. The ability of rhizobia to nodulate plants and reduce $\mathrm{N}_{2}$ is conferred by genes that are plasmid-borne in many species (Pueppke, 1996), and the lateral transfer

\footnotetext{
† Present address: Parasite Molecular Biology and Biochemistry Unit, Department of Infectious and Tropical Diseases, London School of Hygiene and Tropical Medicine, Keppel Street, London WC1E 7HT, UK.

¥ Present address: CEH Oxford, Mansfield Road, Oxford OX1 3SR, UK. § Present address: Unité d'Ecologie et Physiologie du Système Digestif, INRA Centre de Recherche de Jouy-en-Josas, 78352 Jouy-en-Josas Cedex France.

|| Present address: Molecular Medicine Centre, University of Edinburgh, Western General Hospital, Edinburgh EH4 2XU, UK.

The atpD and $\operatorname{rec} A$ sequences and details of the SimPlot analyses are available as supplementary material in IJSEM Online (http:// ijs.sgmjournals.org/).

Abbreviations: HKY85, Hasegawa-Kishino-Yano model; K2P, Kimura's two-parameter model; SSU, small subunit rRNA.

The EMBL accession numbers for the sequences reported in this study are AJ294386-AJ294409 (atpD) and AJ294363-AJ294385 (recA).
}

of these genes is the most likely explanation for their occurrence within several distinct clades of subgroup 2 of the $\alpha$-Proteobacteria (Dobert et al., 1994; Kaijalainen \& Lindström, 1989; Lindström et al., 1995; Young, 1998; Young \& Johnston, 1989). The phylogeny of the nodulation genes is quite different from that of the small subunit rRNA (SSU or 16S rRNA) genes in these bacteria. As in other bacterial groups, the SSU phylogeny has had a major influence on our current perception of evolutionary relationships among rhizobia (Willems \& Collins, 1993; Young, 1996; Young et al., 1991). More than 20 species have been described, and they are classified into the genera Rhizobium, Sinorhizobium, Allorhizobium, Mesorhizobium, Bradyrhizobium and Azorhizobium as well as 'Methylobacterium nodulans' (de Lajudie et al., 1994, 1998b; Dreyfus et al., 1988; Jarvis et al., 1997; Jordan, 1982; Sy et al., 2001). For current nomenclature, see J. P. Euzéby's List of Bacterial Names with Standing in Nomenclature (http:// www.bacterio.cict.fr/).

The genera Bradyrhizobium and Azorhizobium have many phenotypic differences from the others, includ- 
ing much slower growth on laboratory media (Dreyfus et al., 1988; Fred et al., 1932; Jordan, 1982). They are also fairly distant in the SSU phylogeny, being no more related to the other rhizobia, or to each other, than are many non-symbiotic bacteria such as Beijerinckia indica or Blastochloris (Rhodopseudomonas) viridis (Young, 1996; Young \& Haukka, 1996). 'Methylobacterium nodulans' is the name suggested for a recently discovered fourth group of root-nodule bacteria that are methylotrophic and closely related to known Methylobacterium species (Sy et al., 2001). The other rhizobia, known collectively as the fast-growers, are more closely related, but their clade in the SSU phylogeny (Maidak et al., 2000) also includes Agrobacterium (plant gall-formers), Phyllobacterium (leaf and rhizosphere colonists), Mycoplana (branching soil bacteria), Brevundimonas bullata (formerly Mycoplana bullata, see Abraham et al., 1999) and possibly the animal pathogens Bartonella and Brucella (Moreno et al., 1990; Weisburg et al., 1985; Young et al., 1991).

There has been controversy over the relationship between Agrobacterium and Rhizobium, which have long been recognized as close relatives (Fred et al., 1932). Some authors suggested that Agrobacterium should be subsumed into Rhizobium (de Ley, 1968; Graham, 1964, 1976; Heberlein et al., 1967; Kerr, 1992; Sawada et al., 1993; White, 1972), but the splitting of Sinorhizobium and Mesorhizobium from Rhizobium weakened the case for such an amalgamation because it was not clear whether Agrobacterium formed a monophyletic clade with Rhizobium sensu stricto. In the SSU phylogeny, Rhizobium leguminosarum, Rhizobium etli and Rhizobium tropici form a clade, recently joined by Rhizobium gallicum (Amarger et al., 1997) and Rhizobium mongolense (van Berkum et al., 1998). This clade includes Agrobacterium rhizogenes, whose SSU is so similar to that of Rhizobium tropici that one might suggest they were conspecific (Young \& Haukka, 1996). A second clade is formed by Agrobacterium tumefaciens and Agrobacterium rubi and, in some SSU phylogenies, this is joined peripherally by Agrobacterium vitis, Rhizobium galegae and, more recently, Rhizobium huautlense (Wang et al., 1998) and Allorhizobium undicola (de Lajudie et al., 1998b). Young et al. (2001) have recently proposed the inclusion of Agrobacterium and Allorhizobium in Rhizobium. This proposal is supported by a maximumlikelihood analysis of the SSU data that provides stronger evidence for the monophyly of this expanded genus Rhizobium and it sidesteps the necessity to resolve the phylogenetic uncertainties within it. It does, however, create a genus that has much greater SSU diversity than any of the other rhizobial genera. For clarity, we have retained the separate names in this paper.

The enormous success of SSU sequencing as an approach to bacterial systematics relies on the assumption that the evolutionary relationships of bacteria are reliably reflected in their rRNA genes, but gene trees are not necessarily an accurate represen- tation of the species tree if there is exchange of chromosomal genes among the bacteria in question (Pamilo \& Nei, 1988). It is clearly desirable to examine genes other than SSU in order to confirm the relationships among the rhizobia and to clarify those that are ambiguous in the SSU phylogeny. We recently presented phylogenies for some species of fast-growing rhizobia (but not agrobacteria or other non-rhizobia) based on the two glutamine synthetase (GS) loci (Turner \& Young, 2000). The phylogeny of the GSI gene is very similar to that of SSU, with well-supported clades for Mesorhizobium, Sinorhizobium and Rhizobium (Rhizobium leguminosarum, Rhizobium etli and Rhizobium tropici), while Rhizobium galegae occupies a position intermediate between Rhizobium and Sinorhizobium. The GSII phylogeny is similar in most respects, but Rhizobium galegae is closely allied with Rhizobium leguminosarum and Rhizobium etli, Mesorhizobium huakuii is closer to Rhizobium than to Mesorhizobium and the Bradyrhizobium sequence is much closer to those of the fast-growing rhizobia than one would expect. We think these discrepancies probably reflect gene transfer.

In order to assess the impact of gene transfer on the interpretation of single-gene phylogenies, such as those based on SSU, it is necessary to study more loci. We have now examined two additional loci, atpD and rec $A$, in the type strains of representative species of fast-growing rhizobia and their relatives. The rec $A$ gene encodes part of the DNA recombination and repair system and large-scale phylogenies of $\mathrm{rec} A$ in the bacteria are consistent with the corresponding SSU phylogenies (Eisen, 1995; Young, 1998). The atpD gene encodes the beta subunit of the membrane ATP synthase that is essential for energy production. It is a ubiquitous and conserved gene, but there are no published sequences from rhizobia. In the complete $7036071 \mathrm{bp}$ chromosome sequence of Mesorhizobium loti strain MAFF303099 (Kaneko et al., 2000), atpD starts at position 3246882, rec A at 24004 and the two SSU genes at 2745482 and 2752970 . The genes are therefore spaced well apart on the genome.

\section{METHODS}

Isolates. Type strains of rhizobia, Agrobacterium, Phyllobacterium, Brevundimonas and Mycoplana species were obtained as detailed in Table 1. Cultures were grown at $28^{\circ} \mathrm{C}$ in TY medium (Beringer, 1974) and the medium was solidified as required with $1 \%(\mathrm{w} / \mathrm{v})$ agar.

Molecular methods. DNA was purified from liquid cultures as described by Laguerre et al. (1992). Oligonucleotide primers for $\operatorname{rec} A$ and $a t p D$ were designed from alignments of published nucleotide sequences and more robust primers were subsequently designed on the basis of the early sequences obtained. The primers are described in Table 2 and were used for both PCR and sequencing reactions. Purified DNA was added to a $50 \mu \mathrm{l}$ PCR mixture [200 mM dNTP, $1.5 \mathrm{mM} \mathrm{MgCl}_{2}, 10$ pmol each primer, $1 \mathrm{U}$ Taq DNA polymerase and $1 \times$ reaction buffer (Promega)] and incubated at $95^{\circ} \mathrm{C}$ for $5 \mathrm{~min}$ followed by 30 rounds of thermal cycling $\left(94{ }^{\circ} \mathrm{C}\right.$ for $45 \mathrm{~s}, 50^{\circ} \mathrm{C}$ for $60 \mathrm{~s}$ and $74{ }^{\circ} \mathrm{C}$ for $90 \mathrm{~s}$ in a 
Table 1. Bacterial strains and sequences used in this study

Source of strains: USDA, USDA-ARS National Rhizobium Germplasm Collection, Soybean and Alfalfa Research Laboratory, Beltsville, MD, USA; NCPPB, National Collection of Plant Pathogenic Bacteria, Central Science Laboratory, MAFF, Sand Hutton, York, UK; HAMBI, The Culture Collection, Department of Applied Chemistry and Microbiology, University of Helsinki, Finland; A321 ${ }^{\mathrm{T}}$, Sophie Rome, Laboratoire d'Ecologie Microbienne du Sol UMR CNRS 5557, Villeurbanne, France.

\begin{tabular}{|c|c|c|c|c|}
\hline \multirow[t]{2}{*}{ Species } & \multirow[t]{2}{*}{ Type strain } & \multicolumn{3}{|c|}{ Sequence accession number* } \\
\hline & & SSU & atpD & $\operatorname{rec} A$ \\
\hline Rhizobium etli & USDA $9032^{\mathrm{T}}$ & $\mathrm{U} 28916^{a}$ & AJ294404 & AJ294375 \\
\hline Rhizobium galegae & USDA $4128^{\mathrm{T}}$ & $\mathrm{X} 67226^{b}$ & AJ294406 & AJ294378 \\
\hline Rhizobium leguminosarum bv. viciae & USDA $2370^{\mathrm{T}}$ & $\mathrm{U} 29386^{a}$ & AJ294405 & AJ294376 \\
\hline Rhizobium tropici $\mathrm{A}$ & USDA $9039^{\mathrm{T}}$ & $\mathrm{X} 67233^{b}$ & AJ294396 & AJ294372 \\
\hline Rhizobium tropici $\mathrm{B}$ & USDA 9030 & $\mathrm{U} 89832^{c}$ & AJ294397 & AJ294373 \\
\hline Agrobacterium rhizogenes & NCPPB $2991^{\mathrm{T}}$ & $\mathrm{X} 67224^{b}$ & AJ294398 & AJ294374 \\
\hline Agrobacterium tumefaciens & NCPPB $2437^{\mathrm{T}}$ & $\mathrm{X} 67223^{b}$ & AJ294407 & AJ294377 \\
\hline Sinorhizobium fredii & USDA $205^{\mathrm{T}}$ & $\mathrm{X} 67231^{b}$ & AJ294402 & AJ294379 \\
\hline Sinorhizobium meliloti & USDA $1002^{\mathrm{T}}$ & $\mathrm{X} 67222^{b}$ & AJ294400 & AJ294382 \\
\hline Sinorhizobium medicae & $\mathrm{A} 321^{\mathrm{T}}$ & $\mathrm{L}^{3} 9882^{d}$ & AJ294401 & AJ294381 \\
\hline Sinorhizobium sahelense & HAMBI $217^{\mathrm{T}}$ & $\mathrm{X} 68390^{e}$ & AJ294399 & AJ294380 \\
\hline Sinorhizobium terangae & HAMBI $220^{\mathrm{T}}$ & $\mathrm{X} 68388^{e}$ & AJ294403 & AJ294383 \\
\hline Mesorhizobium ciceri & USDA $3383^{\mathrm{T}}$ & $\mathrm{U} 07934^{f}$ & AJ294395 & AJ294367 \\
\hline Mesorhizobium huakuii & USDA $4779^{\mathrm{T}}$ & $\mathrm{D} 12797^{g}$ & AJ294394 & AJ294370 \\
\hline Mesorhizobium loti & USDA $3471^{\mathrm{T}}$ & $\mathrm{X} 67229^{b}$ & AJ294393 & AJ294371 \\
\hline Mesorhizobium mediterraneum & USDA $3392^{\mathrm{T}}$ & $\mathrm{L} 38825^{h}$ & AJ294391 & AJ294369 \\
\hline Mesorhizobium tianshanense & USDA $3592^{\mathrm{T}}$ & $\mathrm{AF} 041447^{i}$ & AJ294392 & AJ294368 \\
\hline Bradyrhizobium japonicum & USDA $6^{\mathrm{T}}$ & $\mathrm{U} 69638^{j}$ & AJ294388 & - \\
\hline Azorhizobium caulinodans & USDA $4892^{\mathrm{T}}$ & $\mathrm{X} 67221^{b}$ & AJ294389 & AJ294363 \\
\hline Phyllobacterium rubiacearum & ATCC $43591^{\mathrm{T}}$ & $\mathrm{D} 12790^{g}$ & AJ294386 & AJ294366 \\
\hline Phyllobacterium myrsinacearum & ATCC $43590^{\mathrm{T}}$ & $\mathrm{D} 12789^{g}$ & AJ294387 & AJ294365 \\
\hline Mycoplana dimorpha & ATCC $4279^{\mathrm{T}}$ & $\mathrm{D} 12786^{g}$ & AJ294408 & AJ294385 \\
\hline Mycoplana ramosa & ATCC $49678^{\mathrm{T}}$ & $\mathrm{D} 10463^{k}$ & AJ294409 & AJ294384 \\
\hline Brevundimonas bullata & ATCC $4278^{\mathrm{T}}$ & $\mathrm{D} 12785^{g}$ & AJ294390 & AJ294364 \\
\hline Rhodobacter capsulatus & & $\mathrm{D} 16428^{l}$ & $\mathrm{X} 99599^{q}$ & $\mathrm{X} 82183^{v}$ \\
\hline Rhodobacter sphaeroides & & $\mathrm{X} 53853^{m}$ & - & $\mathrm{X} 72705^{w}$ \\
\hline Rhodobacter blasticus & & - & $\mathrm{Z} 00018^{r}$ & - \\
\hline Rickettsia prowazekii & & $\mathrm{M} 21789^{n}$ & $\mathrm{AJ} 235273^{s}$ & $\mathrm{U} 01959^{x}$ \\
\hline Helicobacter pylori & & $\mathrm{U} 01330^{\circ}$ & $\mathrm{AF} 004014^{t}$ & $\mathrm{U} 13756^{y}$ \\
\hline Pirellula marina & & $\mathrm{X} 62912^{p}$ & $\mathrm{X} 57204^{u}$ & - \\
\hline
\end{tabular}

* Sequences in bold were determined in this study. Sources of published sequences: $a$, van Berkum et al. (1996); $b$, Willems \& Collins (1993); c, van Berkum et al. (1998); $d$, Rome et al. (1996); e, de Lajudie et al. (1994); $f$, Nour et al. (1994); g, Yanagi \& Yamasato (1993); $h$, Nour et al. (1995); $i$, Wang et al. (1999); $j$, Barrera et al. (1997); $k$, Sakurada et al. (1996); $l$, Hiraishi \& Ueda (1994); $m$, Dryden \& Kaplan (1990); $n$, Weisburg et al. (1989); o, Eckloff et al. (1994); p, Liesack et al. (1992); q, Borghese et al. (1998); $r$, Tybulewicz et al. (1984); s, Andersson et al. (1998); $t$, McGowan et al. (1997); u, Ronner et al. (1991); v, Fernandez de Henestrosa et al. (1995); w, Calero et al. (1994); x, Dunkin \& Wood (1994); y, Thompson \& Blaser (1995).

PTC-100 thermocycler; M J Research, Inc.). PCR products were evaluated on a $1 \%$ agarose gel stained with ethidium bromide. Unincorporated primers and dNTPs were removed from PCR products with Qiaquick PCR purification kits (Qiagen) or, if necessary, products were gel-purified and extracted with Qiagen kits. Purified DNA was sequenced using the dideoxynucleotide chain-termination method with fluorescent ddNTPs from Applied Biosystems on an ABI 377 Prism automated DNA sequencer, in accordance with the manufacturer's instructions. Faint PCR products were cloned into a sequencing vector (pGEM-T; Promega) and transformed into competent Escherichia coli XL-1 Blue before sequencing using T7 and SP6 primers. To check the location of the genes, plasmids were separated by the Eckhardt method of in-well lysis (Eckhardt, 1978; Wheatcroft et al., 1990), transferred to nylon membranes and hybridized with PCR products of each gene amplified from Rhizobium leguminosarum USDA $2370^{\mathrm{T}}$ using the DIG detection kit (Boehringer).

Phylogenetic analysis. Nucleotide alignments of partial rec $A$, atpD and SSU sequences were assembled using CLUSTAL $\mathrm{X}$ (Thompson et al., 1997) and optimized by hand. Molecular phylogenies were reconstructed using the neighbour-joining method (Saitou \& Nei, 1987), with distances estimated using Jukes-Cantor, Kimura's two-parameter (K2P), Galtier and Gouy, Hasegawa-Kishino-Yano (HKY85), Log-det and 
Table 2. Primers used for PCR and sequencing

\begin{tabular}{|c|c|c|c|c|}
\hline Gene & Position* & Direction & Primer length (bases) & Primer sequence $\left(5^{\prime}-3^{\prime}\right) \dagger$ \\
\hline $\operatorname{rec} A$ & 6 & Forward & 26 & CGK CTS GTA GAG GAY AAA TCG GTG GA \\
\hline $\operatorname{rec} A$ & 63 & Forward & 23 & ATC GAG CGG TCG TTC GGC AAG GG \\
\hline $\operatorname{rec} A$ & 504 & Reverse & 20 & TTG CGC AGC GCC TGG CTC AT \\
\hline recA & 555 & Reverse & 26 & CGR ATC TGG TTG ATG AAG ATC ACC AT \\
\hline atpD & 273 & Forward & 21 & SCT GGG SCG YAT CMT GAA CGT \\
\hline atpD & 294 & Forward & 20 & ATC GGC GAG CCG GTC GAC GA \\
\hline atpD & 771 & Reverse & 23 & GCC GAC ACT TCC GAA CCN GCC TG \\
\hline
\end{tabular}

* First base amplified after the primer, relative to the start of the recA gene of Rhizobium leguminosarum (X59956) or the atpD gene of Rhodobacter capsulatus (X99599).

$\uparrow$ Mixtures of bases used at certain positions are given as: K, T or G; S, G or C; Y, C or T; R, A or G; M, A or C; N, any base.

Tajima and Nei models using CLUSTAL X, PHYLOWIN (Galtier et al., 1996) and PAUP*4.0 (Swofford, 1997), with 1000 bootstrap replications.

Maximum-likelihood analysis was performed using three different software implementations. In fastDNAml (Olsen et al., 1994), which uses the F84 model of nucleotide change, global searches were combined with a reiterative jumble of the taxon order and each search was repeated until three identical likelihoods were obtained. The genetic algorithm program GAML (Lewis, 1998) uses the HKY85 model and was run with 10 individuals, with two copies of the fittest always held over, and crossover, branch-length mutation and topological mutation probabilities all set to $0 \cdot 4$. Finally, PAUP*4.0 (Swofford, 1997) was used with the HKY85 model incorporating a discrete gamma $(\Gamma)$ distribution of sitespecific rates and heuristic searches were conducted using the tree bisection-reconnection method for more than 1500 branch rearrangements. Maximum-likelihood estimates of transition/transversion ratios were obtained by a manual optimization using HKY85. Base frequencies and the proportion of invariant sites were estimated directly from empirical data. The estimate of the shape parameter, $\alpha$, of the $\Gamma$ distribution for three discrete rate categories was obtained through an automated maximum-likelihood search strategy incorporating all a priori parameters described.

The $\chi^{2}$ test of homogeneity of base frequencies, $p$-distances, the skewness statistic of tree length distributions (10000 random trees) and the partition homogeneity test (1000 random partitions) were calculated using PAUP*4.0. Kishino-Hasagawa tests were performed using fastDNAml and PAUP*4.0. Alternative phylogeny branching orders were obtained using MacClade (Maddison \& Maddison, 1992).

The Windows program SimPlot (S. C. Ray; http:// www.med.jhu.edu/deptmed/sray/download/) was used to plot pairwise sequence similarities for a sliding window along the alignments and for bootscanning, that is, plotting bootstrap support for pairings of taxa in neighbour-joining trees using a sliding window (Salminen et al., 1995).

\section{RESULTS}

\section{DNA sequencing and gene location}

PCR amplification and sequencing of rhizobium type strains provided at least $450 \mathrm{bp}$ of reliable atpD sequence for all 25 type strains in the analysis and $441 \mathrm{bp}$ of reliable $\operatorname{rec} A$ sequence for 24 type strains. These sequences are available as supplementary data

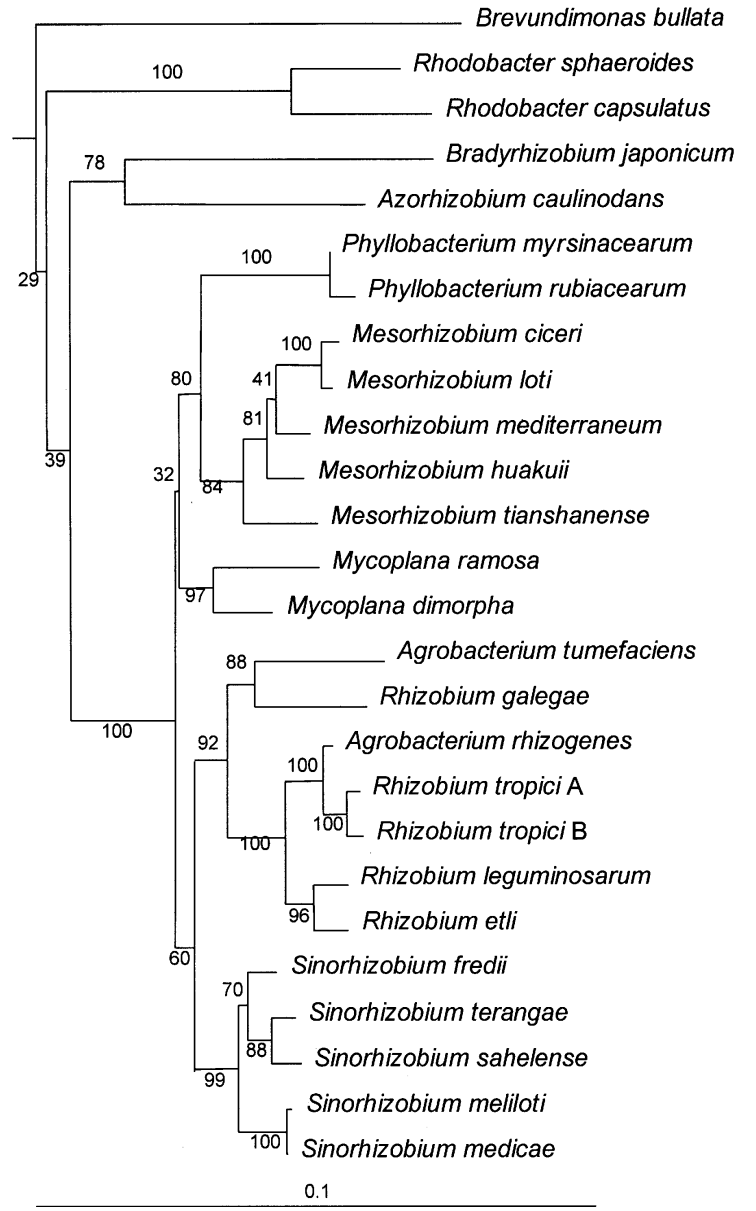

Fig. 1. Neighbour-joining phylogeny for SSU (16S rRNA) genes of type strains of rhizobia and relatives, based on published sequences (Table 1). The tree is rooted using the sequence from Rickettsia prowazekii (not shown). Alignment length was $1400 \mathrm{bp}$, positions with gaps were omitted, K2P distance correction applied. Percentage bootstrap support (1000 replicates) is shown for each internal branch.

in IJSEM Online (http://ijs.sgmjournals.org/). Repeated attempts to amplify and sequence Bradyrhizobium japonicum recA were unsuccessful. The 
reasons for this are not known. The alignments used for phylogenetic analysis corresponded to nucleotides 301-746 in the Rhodobacter capsulatus atpD coding sequence (accession no. X99599) and 75-515 in the Rhizobium leguminosarum recA coding sequence (X59956). The alignment lengths were $461 \mathrm{bp}$ for atpD and $441 \mathrm{bp}$ for recA. Labelled probes prepared from the atpD and recA genes of Rhizobium leguminosarum hybridized to sheared DNA of each of the strains on Eckhardt plasmid gels but not to plasmid bands (data not shown). We conclude that all the genes we sequenced are chromosomal.

\section{Data robustness}

All atpD, $\operatorname{rec} A$ and SSU datasets and subsets were assessed using the $\chi^{2}$ homogeneity test of base frequencies. Only the extensively rooted ('full') rec $A$ dataset described below showed significant variation $(P<0.01$, with $P>0.39$ in all other cases). All phylogenies also showed $p$-distances below $75 \%$ before and after the removal of invariant sites. Furthermore, phylogenies constructed using only third codon positions were broadly congruent with those produced using all three codon positions. Finally, all datasets showed highly significant phylogenetic structure $\left(P<0.01 ; \mathrm{g}_{1}=-0.63\right.$ for 148 informative sites, -0.6216 for 214 informative sites and -0.667 for 392 informative sites for full datasets of $\operatorname{rec} A$, atpD and SSU, respectively) using the skewness statistic of tree length distribution (Hillis \& Huelsenbeck, 1992).

The datasets therefore show strong phylogenetic signal and provide no evidence of saturation. Although variation in base frequency was observed in $\operatorname{rec} A$, the distant outgroups were maintained for the preliminary calculations to ensure consistent rooting.

\section{Neighbour-joining phylogeny}

Neighbour-joining phylogenies of atpD and $\operatorname{rec} A$ were constructed for the 25 type strains sequenced in this study (Rhizobium, Sinorhizobium, Mesorhizobium, Bradyrhizobium, Azorhizobium, Agrobacterium, Phyllobacterium, Brevundimonas and Mycoplana species) plus published outgroup sequences and for SSU of the same species using published sequences. Each phylogeny was rooted using Helicobacter pylori and (for SSU and atpD) Pirellula marina, both of which are unambiguously external to the $\alpha$ Proteobacteria. For SSU, a more comprehensive phylogeny containing an additional 174 taxa of the $\alpha$ Proteobacteria sharing an ancestral node with Rhodospirillum was also constructed. In all cases, Rhodobacter sequences were external to the clade that included all rhizobia and Rickettsia prowazekii sequences were more distant still. Rickettsia was subsequently used as the outgroup and the more remote outgroups were removed. Neighbour-joining phylogenies were constructed for each dataset using the six distance-correction models described in Methods. Those clades that had strong bootstrap

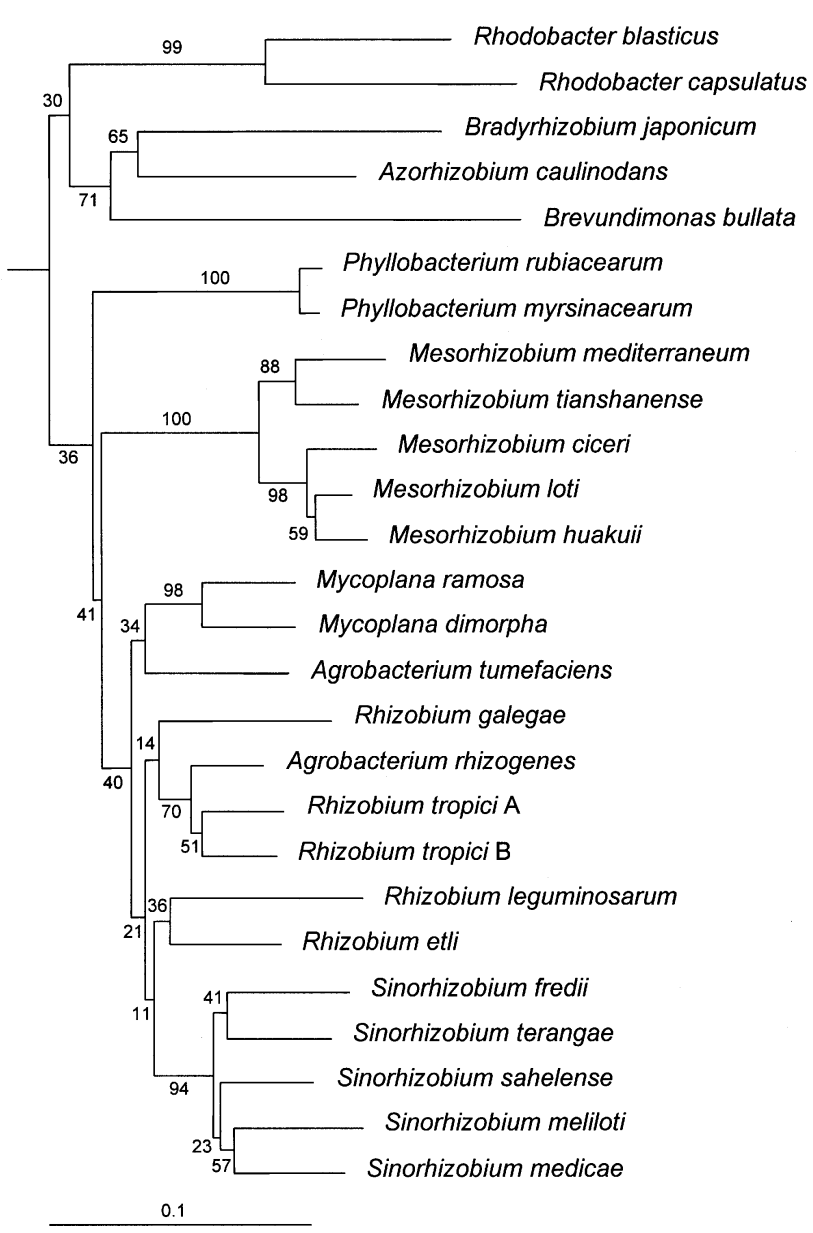

Fig. 2. Neighbour-joining phylogeny for partial atp $D$ sequences (alignment length $461 \mathrm{bp}$ ) of type strains of rhizobia and relatives. Other details as Fig. 1.

support were found consistently using all models and the trees obtained with the K2P model are shown (Figs 1-3), since more complex models gave substantially similar results.

For each of the genes (SSU, $\operatorname{rec} A$, atpD), the five Mesorhizobium species formed a strongly supported monophyletic group (84-100\% of bootstraps), as did the five species of Sinorhizobium (82-99\%). Support for Mesorhizobium in the SSU tree increased from 84 to $100 \%$ if the Phyllobacterium sequences were omitted. The status of the other fast-growing rhizobia (the genus Rhizobium) was less clear-cut and has to be considered jointly with that of Agrobacterium. The close similarity between Agrobacterium rhizogenes and Rhizobium tropici, previously noted on the basis of SSU and supported here by $100 \%$ of bootstraps, was confirmed by both the other genes $(99 \%$ for recA, $70 \%$ for atpD). In the SSU tree, Rhizobium leguminosarum and Rhizobium etli were closely related $(96 \%)$ and formed the strongly supported sister group of the Rhizobium tropici-Agrobacterium rhizogenes clade (100\%). Rhizobium galegae and Agrobacterium tumefaciens were associated with these species (92\%) 


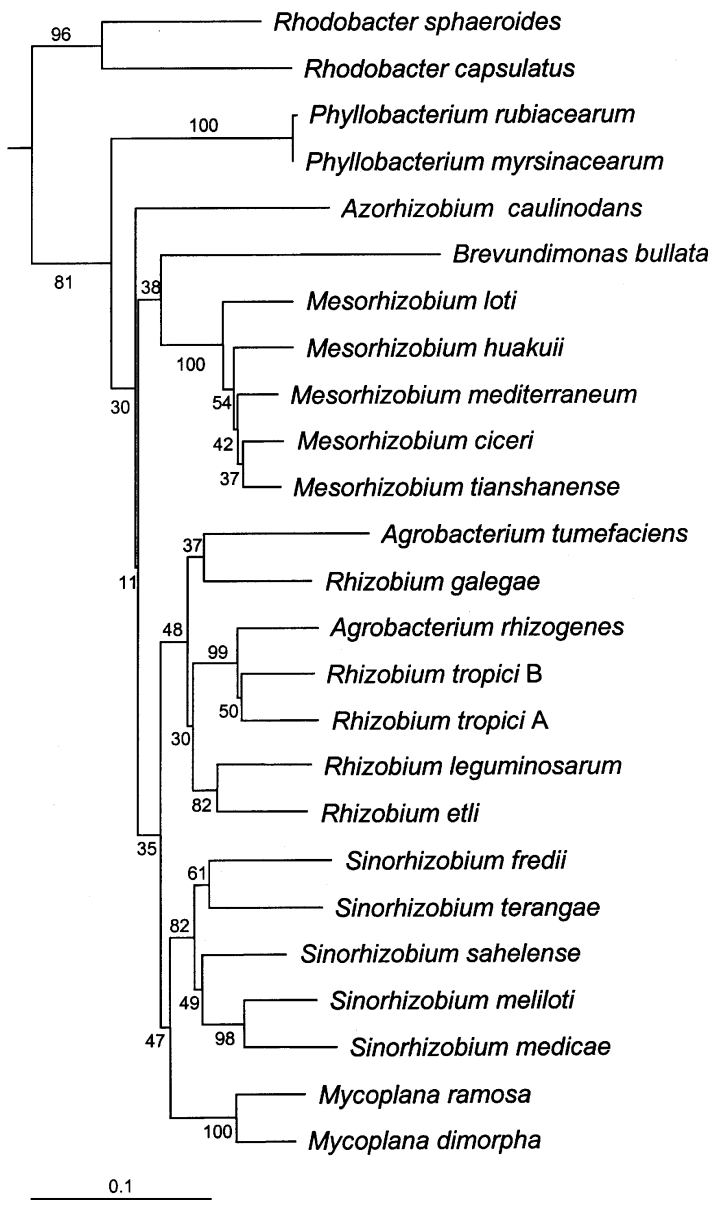

Fig. 3. Neighbour-joining phylogeny for partial $\operatorname{rec} A$ sequences (alignment length $441 \mathrm{bp}$ ) of type strains of rhizobia and relatives. Other details as Fig. 1.

and formed a clade together $(88 \%)$. All these relationships were also seen in the rec $A$ tree, though with poorer bootstrap support. In the atpD tree, bootstrap support was generally poor, and the Rhizobium-Agrobacterium clade was not supported, though, on the other hand, it was not excluded either.

The phylogenetic positions of the non-rhizobial genera Mycoplana, Brevundimonas and especially Phyllobacterium were less robust and this contributes markedly to the ambiguity in parts of the trees. Mycoplana ramosa and Mycoplana dimorpha were sister taxa in the trees for all three genes, with good bootstrap support (97-100\%), and formed an independent clade not associated closely with any other genus. For all three genes, the Brevundimonas bullata branch was unusually long and its position within the phylogeny was poorly supported.

The two Phyllobacterium species, Phyllobacterium rubiacearum and Phyllobacterium myrsinacearum, were almost identical in sequence at all three loci, but their placement in the trees was uncertain. The association with Mesorhizobium seen for SSU (Fig. 1) was not supported by the other genes, which suggested a deeper placement (Figs 2 and 3). Removal of the two Phyllobacterium recA sequences did not alter the structure of the remainder of the tree at all, but dramatically improved support for some clades. Notably, support for Rhizobium-Agrobacterium rose from 48 to $89 \%$.

The atpD tree, on the other hand, which generally had poorer resolution than that for $\operatorname{rec} A$, was not significantly altered by the removal of Phyllobacterium and/or Brevundimonas sequences. Removal of Rickettsia, the outgroup, had a more substantial effect on the atpD tree: support for the crown group (Phyllobacterium to Sinorhizobium) increased from 36 to $74 \%$, while the root of this group shifted strongly onto the Mesorhizobium branch, so that the clade that excludes Mesorhizobium (but includes Phyllobacterium) received $98 \%$ bootstrap support. Other relationships were not significantly affected and the improvements in support occurred whether or not Phyllobacterium and/or Brevundimonas sequences were included in the tree.

The program SimPlot was used to look for possible reasons for the unstable behaviour of some sequences. Pairwise similarities were plotted for a $100 \mathrm{bp}$ sliding window along the length of each gene and bootscanning analyses were made to highlight changes in support for different tree topologies. For the $5^{\prime}$ part of the rec $A$ sequence, Brevundimonas was associated with Mesorhizobium and Phyllobacterium lay near the base of the tree, while the situation was reversed in the $3^{\prime}$ part. This explains the low bootstrap values $(30,11$, $38 \%$ ) in Fig. 3. In the SSU, the Rhizobium galegae sequence generally resembles that of Agrobacterium tumefaciens except for a cluster of phylogenetically informative sites at around position 1000 that match Rhizobium leguminosarum instead. This reduced the confidence with which Rhizobium galegae could be placed in the tree and might perhaps reflect a recombination event. Details of the analyses are available as supplementary information in IJSEM Online (http://ijs.sgmjournals.org/).

\section{Maximum-likelihood phylogeny}

Maximum-likelihood models were constructed as described in Methods. In all cases, the HKY $85+\Gamma$ model (which allows nucleotide positions to have different evolutionary rates assigned from a gamma distribution) showed a significant improvement on the HKY85 model, according to the likelihood ratio test (Yang et al., 1994). As in the neighbour-joining trees, the position of Phyllobacterium was ambiguous for each of the three genes. For the HKY85 model, Phyllobacterium formed an outgroup to the fastgrowing rhizobia, whilst, for the HKY $85+\Gamma$ model, it occurred within the fast-growing rhizobia.

Identical topologies between maximum-likelihood and neighbour-joining methods were observed within Sinorhizobium for all genes and within the Rhizobium-Agrobacterium clade for SSU. Elsewhere, 


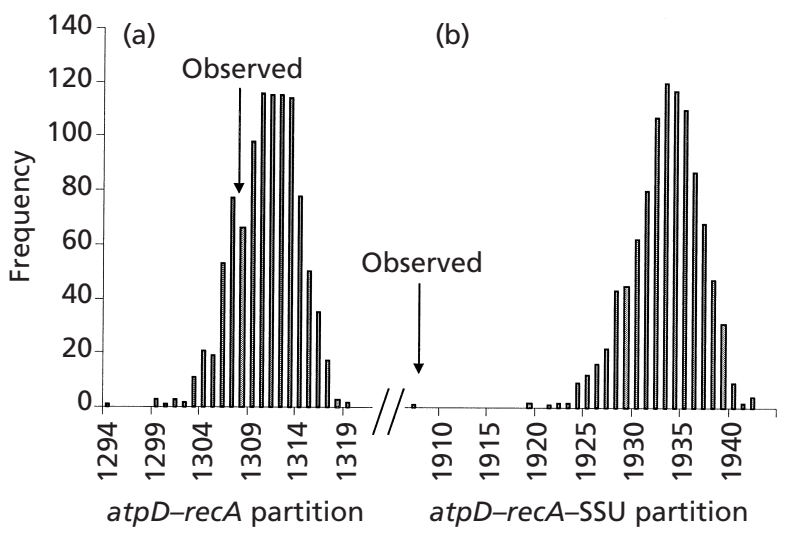

Length difference for random partitions

Fig. 4. Partition-homogeneity test to determine whether data from different genes can be combined. The incongruence length difference (the extra steps required when data for genes are combined) is compared with that for 1000 random partitions of the variable sites. (a) Combination of atpD and $\operatorname{rec} A$; (b) combination of atpD, recA and SSU sequences, for the 23 taxa sequenced in this study.

numerous topological differences between neighbourjoining and maximum-likelihood methods were observed, but none involved branches that were well supported by neighbour-joining bootstrap analysis.

\section{Partition homogeneity and combined data}

A more reliable phylogeny might be obtained by using combined data for all three genes. The partition homogeneity test (Cunningham, 1997; Farris et al., 1994; Mickevich \& Farris, 1981) was applied to check whether trees for the different genes were sufficiently similar in rates of divergence and branching order that it would be legitimate to combine the data. The test calculates how much longer the combined parsimony tree is than the sum of the separate trees, and compares this difference to the expected distribution estimated by allocating the data randomly into partitions of the same size as the genes. The atpD and rec $A$ sequences for the 23 sequenced type strains (the taxa in Fig. 3 minus Rickettsia and Rhodobacter) were combined and analysed using a two-partition test, one data partition corresponding to each gene. A three-partition test was conducted on the atpD, $\operatorname{rec} A$ and SSU data. Invariant characters were removed for all analyses. Parsimony step-length homogeneity was supported for the atpD + rec $A$ test $(P=0.25)$ but rejected for the atp $D+\operatorname{rec} A+\mathrm{SSU}$ test $(P<0 \cdot 001)$, as shown in Fig. 4 . The latter result was confirmed using a two-partition test containing atpD and $r e c A$ in one partition and SSU in the second for 100 randomized data partitions $(P<0.01)$. These results permit us to combine the atpD and $\operatorname{rec} A$ data, but suggest that the SSU data should be treated separately. Similar tests with a reduced dataset of just the 18 rhizobia and agrobacteria led to the same conclusion $(P=0.256$ for $a t p D+\operatorname{rec} A, P<0.001$ for $a t p D+\operatorname{rec} A+\mathrm{SSU})$.
Maximum-likelihood and neighbour-joining phylogenies for the combined $a t p D$ and $r e c A$ sequences were compared with the corresponding SSU phylogenies. Trees were constructed with various combinations of the 23 taxa. Bootstrap support for the RhizobiumAgrobacterium clade was still low (58\%) in the neighbour-joining analysis of the combined atp $D+\operatorname{rec} A$ data if all taxa were retained, though higher than for either gene separately ( $48 \%$ for $r e c A$, $<50 \%$ for atpD). However, removing nonrhizobia, and especially the troublesome Phyllobacterium sequences, increased support to $93 \%$. Trees that include just rhizobia and agrobacteria are shown in Fig. 5.

The robustness of the Rhizobium-Agrobacterium clade within the 23-taxon atpD + rec $A$ tree was also investigated by constructing 28 alternative topologies for the disruption of monophyly by moving combinations of Rhizobium leguminosarum, Rhizobium etli and Rhizobium galegae, assessed using the Kishino-Hasagawa test on the HKY85 $+\Gamma$ maximum-likelihood model. This test determines whether an alternative tree is significantly less likely than the best tree, taking into account the observed variance in log-likelihood difference across nucleotide sites (log-likelihood, ln L, is the natural logarithm of the likelihood, so a reduction of 1 in $\ln \mathrm{L}$ represents a tree that is 2.718 times less likely). The rearrangement of highest likelihood was when the Rhizobium leguminosarumRhizobium etli lineage formed a sister group to Sinorhizobium-Mycoplana $(P=0 \cdot 15$; reduction in $\ln$ $\mathrm{L}$ of 8.21). The same placement of Rhizobium galegae or the three-taxon lineage also showed no significant reduction in likelihood $(P \leqslant 0.0568)$. However, placement of Rhizobium leguminosarum-Rhizobium etli or Rhizobium galegae within the Sinorhizobium clade was significantly worse $(P \leqslant 0.0369)$, as was placement on the Mesorhizobium branch $(P \leqslant 0 \cdot 0165)$. Disruption of the Rhizobium leguminosarum-Rhizobium etli lineage was significant in all cases $(P \leqslant 0.0314)$, confirming the neighbour-joining bootstrap support for this clade.

\section{Evidence from insertions and deletions}

There are a number of small insertions and deletions in the atpD alignment that provide additional phylogenetic evidence. Relative to all the other sequences (including outgroups), Azorhizobium caulinodans and Brevundimonas bullata have a $15 \mathrm{bp}$ insertion at position 301 in the alignment and Bradyrhizobium japonicum has a $12 \mathrm{bp}$ insertion at the same place. These insertions are related in sequence and provide good support for the monophyly of these three species, as shown in Fig. 2. All the sequences in Fig. 2, with the exception of those of Brevundimonas bullata and the two Rhodobacter species, have a $3 \mathrm{bp}$ deletion at position 441 relative to the outgroups (Rickettsia has a $3 \mathrm{bp}$ insertion at the same position). If the phylogeny in Fig. 2 is correct, this implies two independent deletions at the same site: one in the BradyrhizobiumAzorhizobium lineage and the other in the ancestor of 


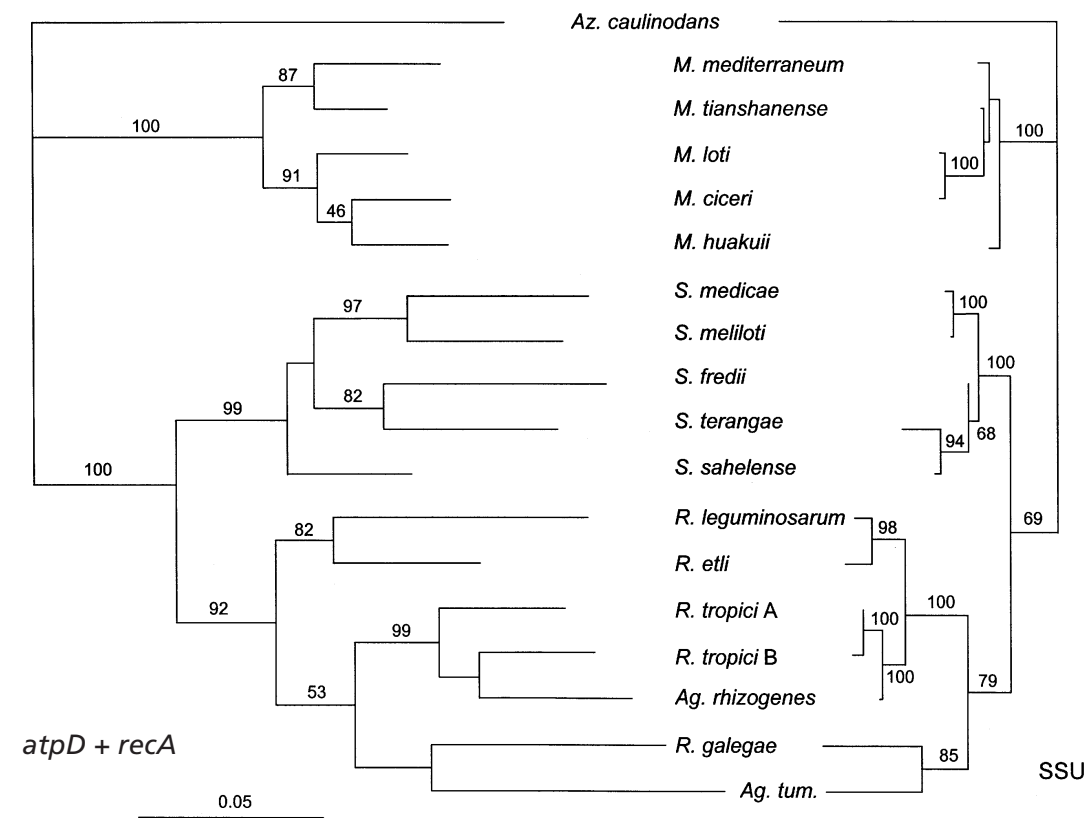

Fig. 5. Comparison of the combined atpDrecA phylogeny for rhizobia and agrobacteria and the corresponding SSU phylogeny. The trees were constructed by the maximum-likelihood method (F84 model), but bootstrap values (percentages of 1000 replicates) are for the corresponding branches in the neighbour-joining tree. Unlabelled branches were not found in the neighbour-joining tree. Genera are abbreviated as: Ag., Agrobacterium; Az., Azorhizobium; M., Mesorhizobium; R., Rhizobium; S., Sinorhizobium. the other species. A plausible alternative is that the Rhodobacter sequences are actually basal to the rest of the taxa in Fig. 2 and that there was a single deletion with a subsequent reinsertion in Brevundimonas (which has a high level of sequence divergence in general).

There are length variants in the SSU alignment, too, but they tend to occur in variable regions in which the exact alignment is uncertain. At around position 950, there are 3 bp missing in Rhizobium leguminosarum, Rhizobium etli, Rhizobium tropici A and B, Rhizobium galegae and Agrobacterium rhizogenes, but not in Agrobacterium tumefaciens. This unites the whole Rhizobium-Agrobacterium cluster except Agrobacterium tumefaciens and supports the bootscan analysis, which suggests that, in this segment of the SSU gene, Agrobacterium tumefaciens is divergent from Rhizobium galegae (see above). There is a similar $3 \mathrm{bp}$ deletion in the Brevundimonas bullata sequence, but this presumably represents convergent evolution, since this sequence is very distant. A deletion of $21 \mathrm{bp}$ at position 1200 is a shared derived character of Brevundimonas and the two Rhodobacter sequences, supporting a Brevundimonas-Rhodobacter clade that is not present in Fig. 1, but is not significantly contradicted. These three sequences also share a TTCG loop at positions 60-63 (all rhizobia have GCAA).

\section{DISCUSSION}

\section{The Mesorhizobium clade}

The genus Mesorhizobium was created to recognize a group of species with distinctive phenotypic properties and forming a clearly defined clade in the SSU phylogeny that was outside the RhizobiumSinorhizobium-Agrobacterium cluster (Jarvis et al., 1997). Our analyses of $a t p D$ and $r e c A$ sequences fully support both the integrity of the Mesorhizobium clade and its placement in the phylogeny. Further evidence is provided by a recent study of glutamine synthetase sequences (Turner \& Young, 2000). The phylogeny of the GSI gene $g \ln A$ yet again places Mesorhizobium as a tight clade outside the fast-growing rhizobia. However, the GSII gene is more equivocal. It is not possible to root the tree unambiguously because this gene is not widespread in bacteria, but the sequences for Mesorhizobium mediterraneum, Mesorhizobium tianshanense, Mesorhizobium ciceri and (less convincingly) Mesorhizobium loti do cluster together. The Mesorhizobium huakuii sequence, on the other hand, shows closer affinity with sequences of the genus Rhizobium. Turner \& Young (2000) suggested that this might be the result of recombination; perhaps replacement of the whole gene, since they found no evidence for a recombination site within the gene. Our $a t p D$ and $\operatorname{rec} A$ data reinforce the view that the SSUbased phylogeny holds for the majority of the genome and that GSII is exceptional and requires a special explanation of this kind.

Mesorhizobium forms a closely knit clade, but relationships among the species are not the same for all genes. For SSU, the Mesorhizobium loti and Mesorhizobium ciceri type strains are very similar, but this is not true for any of the other genes. This is consistent with the finding that Mesorhizobium strains that are virtually identical in SSU sequence may be unrelated in terms of DNA-DNA hybridization (Sullivan et al., 1996) and suggests that there may be recombination of chromosomal genes between Mesorhizobium species.

\section{The Sinorhizobium clade}

Like Mesorhizobium, the genus Sinorhizobium forms a very clearly defined clade in the SSU tree, with a high level of sequence similarity among the species. All the 
sequences from other genes confirm that Sinorhizobium is indeed a clade, with good bootstrap support: atpD, $94 \%$; rec $A, 82 \%$ (atpD and rec $A$ jointly $99 \%$ ), $g \ln A$, $96 \%$ and $g \ln I I, 100 \%$ (Turner \& Young, 2000). All the genes also agree that Sinorhizobium meliloti and Sinorhizobium medicae are sister taxa, but atpD, recA and $g \ln A$ all support a pairing of Sinorhizobium terangae with Sinorhizobium fredii, in contradiction to the pairing of Sinorhizobium terangae and Sinorhizobium sahelense that is strongly supported by SSU sequence and also favoured by $g \ln I I$. Again, this might be interpreted as evidence for recombination between species.

\section{Rhizobium and Agrobacterium}

Almost 70 years ago, Fred et al. (1932) pointed out that agrobacteria and fast-growing rhizobia seemed to be more closely related than either were to bradyrhizobia, an insight that has of course been amply confirmed by modern methods. The amalgamation of Rhizobium and Agrobacterium has been suggested several times without a formal proposal (de Ley, 1968; Graham, 1964, 1976; Heberlein et al., 1967; Kerr, 1992; Sawada et al., 1993; White, 1972), but such a proposal has finally been made (Young et al., 2001). It is certainly true that the species of these two genera do not form two separate clades. One reason for this is easily dealt with: Agrobacterium rhizogenes (also known as biovar 2) is closely similar to Rhizobium tropici in SSU sequence and we see that this relationship also holds for $a t p D$ and $\operatorname{rec} A$. Clearly, these species belong in the same genus.

A deeper problem has been Rhizobium galegae, which usually clusters with Agrobacterium (specifically Agrobacterium vitis) rather than Rhizobium in the SSU phylogeny, as do Rhizobium huautlense (Wang et al., 1998) and Allorhizobium undicola (de Lajudie et al., 1998b). Wang et al. (1998) noted that, as more sequences were added to the RhizobiumAgrobacterium part of the SSU phylogeny, the clustering of Rhizobium galegae with Agrobacterium disappeared. This is consistent with our evidence from the other genes: neither $a t p D$ nor $\operatorname{rec} A$ provides any support for a Rhizobium galegae-Agrobacterium tumefaciens clade or for any other particular association involving either of these species.

Our data suggest that the distinction between Rhizobium and Agrobacterium is less clear-cut than it appears from SSU sequences alone, which could be taken as support for the proposal to amalgamate them (Young et al., 2001). Before doing this, though, it is important to be reasonably confident that the grouping is monophyletic. Considering only the species in our study, bootstrap support is $92 \%$ for SSU (Fig. 1) but only $48 \%$ for $\operatorname{rec} A$ (Fig. 2), while in the atpD tree, Mycoplana and Sinorhizobium cannot be excluded from the clade. In the case of $\operatorname{rec} A$, the poor support is due largely to the two Phyllobacterium sequences, which are highly diverged but share a considerable number of phylogenetically informative sites with Rhizobium-Agrobacterium. The phylogenetic position of Phyllobacterium is uncertain, but the SSU and atpD phylogenies suggest that it does not belong in the Rhizobium-Agrobacterium clade. If only rhizobia and agrobacteria are considered, support for this clade rises to $93 \%$ (Fig. 5). Of course, there are several Agrobacterium and Rhizobium species that were not included in our study, and it will be important to examine their atpD and $\operatorname{rec} A$ sequences before concluding that these genes fully support a RhizobiumAgrobacterium clade.

\section{Phyllobacterium, Mycoplana and Brevundimonas}

While the close similarity of Agrobacterium to Rhizobium is indisputable, the phylogenetic placement of the other non-rhizobia is much more problematic. Brevundimonas bullata is always on a long branch with no close relatives, while the two Mycoplana species consistently cluster together, forming a separate clade at the same level as Rhizobium, Sinorhizobium and Mesorhizobium and not associated closely with any one of these genera. At all three loci, Phyllobacterium myrsinacearum and Phyllobacterium rubiacearum are so closely related that one might question whether they represent distinct species. Their phylogenetic position is, however, very uncertain. The SSU sequences have some affinity with Mesorhizobium and recA with Rhizobium-Agrobacterium, but the Phyllobacterium sequences are too diverged to place stably in the phylogenies. There is certainly little support for the suggestion that Mesorhizobium be placed together with Phyllobacterium in a family Phyllobacteriaceae (http:// www.cme.msu.edu/Bergeys). There is little literature on Phyllobacterium, Mycoplana or Brevundimonas at present, but their pattern of molecular divergence suggests that their evolutionary history may be different from that of the rhizobia.

\section{Next steps in the phylogeny of the rhizobia}

Since this study was initiated, there have been several additions to the rhizobial species list as a result of sampling from a wider range of host-plant species and habitats. Some, such as Rhizobium hainanense (Chen et al., 1997), Rhizobium gallicum (Amarger et al., 1997), Rhizobium mongolense (van Berkum et al., 1998), Mesorhizobium amorphae (Wang et al., 1999), Mesorhizobium plurifarium (de Lajudie et al., 1998a), Sinorhizobium arboris and Sinorhizobium kostiense (Nick et al., 1999), can be placed very firmly within existing clades on the basis of their SSU sequences. While it would be reassuring to confirm these placements using other genes, we would not expect many surprises because our data show that an unambiguous SSU similarity is usually reflected in other genes. More interesting are the new species of less obvious affinity, and further gene sequences from Rhizobium giardinii, Rhizobium huautlense and Allorhizobium undicola would be welcome. 
Despite a greatly broadened sampling of host-plant species and geographical locations, the taxonomic diversity of root-nodule bacteria has, until recently, remained relatively narrow and clearly defined. The new species have fallen mainly within the existing genera or, failing that, between them rather than beyond them. The recent report (Sy et al., 2001) of root-nodule bacteria in the genus Methylobacterium is an exception and represents the first expansion of the known phylogenetic range of rhizobia since the description of Azorhizobium (Dreyfus et al., 1988). Nevertheless, plasmid replicons related to those that carry symbiosis genes in many rhizobia have been found in Paracoccus (Bartosik et al., 1997) and Rhodobacter (unpublished Rhodobacter capsulatus genome sequence at http://rhodo.img.cas.cz/) and there seems no intrinsic reason why the root-nodule symbiosis should not extend to these groups of the $\alpha$ Proteobacteria or even beyond. The broad phylogenetic agreement that we report here is true only for the 'housekeeping' genome and there is now ample evidence that the symbiosis genes have a quite different evolutionary history as a result of horizontal transfer. There are probably other sets of 'contingency genes' that have idiosyncratic phylogenies, but our study indicates that there is a robust and consistent phylogeny for the genomic backbone of housekeeping genes in bacteria.

\section{ACKNOWLEDGEMENTS}

We are grateful for conversations with Sandie Baldauf and Gary Olsen. We thank Peter van Berkum, Kristina Lindström, Sophie Rome and David Stead for sending strains, Allen Mould for DNA sequencing, Jeremy Searle for access to PAUP* and John Robinson and staff at both York and Manchester computer services for technical advice and support. A large proportion of the computation was conducted on the CSAR Origin2000 machine at Manchester Computing. The work was funded by NERC grant GR3/ 10819 and contract BIO4-CT98-0483 (TRAFFIC) from the Commission of the European Communities.

\section{REFERENCES}

Abraham, W.-R., Strömpl, C., Meyer, H. \& 8 other authors (1999). Phylogeny and polyphasic taxonomy of Caulobacter species. Proposal of Maricaulis gen. nov. with Maricaulis maris (Poindexter) comb. nov. as the type species, and emended description of the genera Brevundimonas and Caulobacter. Int $J$ Syst Bacteriol 49, 1053-1073.

Amarger, N., Macheret, V. \& Laguerre, G. (1997). Rhizobium gallicum sp. nov. and Rhizobium giardinii sp. nov., from Phaseolus vulgaris nodules. Int J Syst Bacteriol 47, 996-1006.

Andersson, S. G. E., Zomorodipour, A., Andersson, J. 0. \& 7 other authors (1998). The genome sequence of Rickettsia prowazekii and the origin of mitochondria. Nature 396, 133-140.

Barrera, L. L., Trujillo, M. E., Goodfellow, M., García, F. J., Hernández-Lucas, I., Dávila, G., van Berkum, P. \& MartínezRomero, E. (1997). Biodiversity of bradyrhizobia nodulating Lupinus spp. Int J Syst Bacteriol 47, 1086-1091.

Bartosik, D., Wlodarczyk, M. \& Thomas, C. M. (1997). Complete nucleotide sequence of the replicator region of Paracoccus
(Thiobacillus) versutus pTAV1 plasmid and its correlation to several plasmids of Agrobacterium and Rhizobium species. Plasmid 38, 53-59.

Beringer, J. E. (1974). $\mathrm{R}$ factor transfer in Rhizobium leguminosarum. J Gen Microbiol 84, 188-198.

van Berkum, P., Beyene, D. \& Eardly, B. D. (1996). Phylogenetic relationships among Rhizobium species nodulating the common bean (Phaseolus vulgaris L.). Int J Syst Bacteriol 46, 240-244.

van Berkum, P., Beyene, D., Bao, G., Campbell, T. A. \& Eardly, B. D. (1998). Rhizobium mongolense sp. nov. is one of three rhizobial genotypes identified which nodulate and form nitrogen-fixing symbioses with Medicago ruthenica [(L.) Ledebour]. Int J Syst Bacteriol 48, 13-22.

Borghese, R., Crimi, M., Fava, L. \& Melandri, B. A. (1998). The ATP synthase atpHAGDC (F1) operon from Rhodobacter capsulatus. J Bacteriol 180, 416-421.

Calero, S., Fernandez de Henestrosa, A. R. \& Barbe, J. (1994). Molecular cloning, sequence and regulation of expression of the recA gene of the phototrophic bacterium Rhodobacter sphaeroides. Mol Gen Genet 242, 116-120.

Chen, W.-X., Tan, Z.-Y., Gao, J.-L., Li, Y. \& Wang, E.-T. (1997). Rhizobium hainanense sp. nov., isolated from tropical legumes. Int $J$ Syst Bacteriol 47, 870-873.

Cunningham, C. W. (1997). Can three incongruence tests predict when data should be combined? Mol Biol Evol 14, 733-740.

Dobert, R. C., Breil, B. T. \& Triplett, E. W. (1994). DNA sequence of the common nodulation genes of Bradyrhizobium elkanii and their phylogenetic relationship to those of other nodulating bacteria. Mol Plant Microbe Interact 7, 564-572.

Dreyfus, B., Garcia, J. L. \& Gillis, M. (1988). Characterization of Azorhizobium caulinodans gen. nov., sp. nov., a stem-nodulating nitrogen-fixing bacterium isolated from Sesbania rostrata. Int $J$ Syst Bacteriol 38, 89-98.

Dryden, S. C. \& Kaplan, S. (1990). Localization and structural analysis of the ribosomal RNA operons of Rhodobacter sphaeroides. Nucleic Acids Res 18, 7267-7277.

Dunkin, S. M. \& Wood, D. O. (1994). Isolation and characterization of the Rickettsia prowazekii recA gene. J Bacteriol 176, 1777-1781.

Eckhardt, T. (1978). A rapid method for the identification of plasmid desoxyribonucleic acid in bacteria. Plasmid 1, 584-588.

Eckloff, B. W., Podzorski, R. P., Kline, B. C. \& Cockerill, F. R., III (1994). A comparison of $16 \mathrm{~S}$ ribosomal DNA sequences from five isolates of Helicobacter pylori. Int J Syst Bacteriol 44, 320-323.

Eisen, J. A. (1995). The RecA protein as a model molecule for molecular systematic studies of bacteria: comparison of trees of RecAs and 16S rRNAs from the same species. J Mol Evol 41, 1105-1123.

Farris, J. S., Källersjö, M., Kluge, A. G. \& Bult, C. (1994). Testing significance of incongruence. Cladistics 10, 315-319.

Fernandez de Henestrosa, A. R., Rivera, E. \& Barbe, J. (1995). Non-reciprocal regulation of Rhodobacter capsulatus and Rhodobacter sphaeroides recA genes expression. FEMS Microbiol Lett 129, 175-181.

Fred, E. B., Baldwin, I. L. \& McCoy, E. (1932). Root Nodule Bacteria and Leguminous Plants. Madison, WI: University of Wisconsin.

Galtier, N., Gouy, M. \& Gautier, C. (1996). SEAVIEW and PHYLO_WIN: two graphic tools for sequence alignment and molecular phylogeny. Comput Appl Biosci 12, 543-548. 
Graham, P. H. (1964). The application of computer techniques to the taxonomy of the root-nodule bacteria of legumes. J Gen Microbiol 35, 511-517.

Graham, P. H. (1976). Identification and classification of root nodule bacteria. In Symbiotic Nitrogen Fixation in Plants, International Biological Programme no. 7, pp. 99-112. Edited by P. S. Nutman. London: Cambridge University Press.

Heberlein, G. T., De Ley, J. \& Tijtgat, R. (1967). Deoxyribonucleic acid homology and taxonomy of Agrobacterium, Rhizobium, and Chromobacterium. J Bacteriol 94, 116-124.

Hillis, D. M. \& Huelsenbeck, J. P. (1992). Signal, noise, and reliability in molecular phylogenetic analyses. J Hered $\mathbf{8 3}$, 189-195.

Hiraishi, A. \& Ueda, Y. (1994). Intrageneric structure of the genus Rhodobacter: transfer of Rhodobacter sulfidophilus and related marine species to the genus Rhodovulum gen. nov. Int $J$ Syst Bacteriol 44, 15-23.

Jarvis, B. D. W., Van Berkum, P., Chen, W. X., Nour, S. M., Fernandez, M. P., Cleyet-Marel, J. C. \& Gillis, M. (1997). Transfer of Rhizobium loti, Rhizobium huakuii, Rhizobium ciceri, Rhizobium mediterraneum, and Rhizobium tianshanense to Mesorhizobium gen. nov. Int J Syst Bacteriol 47, 895-898.

Jordan, D. C. (1982). Transfer of Rhizobium japonicum Buchanan 1980 to Bradyrhizobium gen. nov., a genus of slow-growing, root nodule bacteria from leguminous plants. Int $J$ Syst Bacteriol 32, 136-139.

Kaijalainen, S. \& Lindström, K. (1989). Restriction fragment length polymorphism analysis of Rhizobium galegae strains. $J$ Bacteriol 171, 5561-5566.

Kaneko, T., Nakamura, Y., Sato, S. \& 21 other authors (2000). Complete genome structure of the nitrogen-fixing symbiotic bacterium Mesorhizobium loti. DNA Res 7, 331-338.

Kerr, A. (1992). The genus Agrobacterium. In The Prokaryotes - a Handbook on the Biology of Bacteria, pp. 2214-2235. Edited by A. Balows, H. G. Trüper, M. Dworkin, W. Harder \& K.-H. Schleifer. Heidelberg: Springer.

Laguerre, G., Mazurier, S. I. \& Amarger, N. (1992). Plasmid profiles and restriction fragment length polymorphism of Rhizobium leguminosarum bv. viciae in field populations. FEMS Microbiol Lett 101, 17-26.

de Lajudie, P., Willems, A., Pot, B. \& 7 other authors (1994). Polyphasic taxonomy of rhizobia: emendation of the genus Sinorhizobium and description of Sinorhizobium meliloti comb. nov., Sinorhizobium saheli sp. nov., and Sinorhizobium teranga sp. nov. Int J Syst Bacteriol 44, 715-733.

de Lajudie, P., Willems, A., Nick, G. \& 9 other authors (1998a). Characterization of tropical tree rhizobia and description of Mesorhizobium plurifarium sp. nov. Int J Syst Bacteriol 48, 369-382.

de Lajudie, P., Laurent-Fulele, E., Willems, A., Torck, U., Coopman, R., Collins, M. D., Kersters, K., Dreyfus, B. \& Gillis, M. (1998b). Allorhizobium undicola gen. nov., sp. nov., nitrogen-fixing bacteria that efficiently nodulate Neptunia natans in Senegal. Int J Syst Bacteriol 48, 1277-1290.

Lewis, P. O. (1998). A genetic algorithm for maximum-likelihood phylogeny inference using nucleotide sequence data. Mol Biol Evol 15, 277-283.

de Ley, J. (1968). DNA base composition and hybridization in the taxonomy of the phytopathogenic bacteria. Annu Rev Phytopathol 6, 63-90.

Liesack, W., Soller, R., Stewart, T., Haas, H., Giovannoni, S. \& Stackebrandt, E. (1992). The influence of tachytelically (rapidly) evolving sequences on the topology of phylogenetic trees: intrafamily relationships and the phylogenetic position of Planctomycetaceae as revealed by comparative analysis of $16 \mathrm{~S}$ ribosomal RNA sequences. Syst Appl Microbiol 15, 357-362.

Lindström, K., Paulin, L., Roos, C. \& Suominen, L. (1995). Nodulation genes of Rhizobium galegae. In Nitrogen Fixation: Fundamentals and Applications, pp. 365-370. Edited by I. A. Tikhonovich, N. A. Provorov, V. I. Romanov \& W. E. Newton. Dordrecht: Kluwer.

McGowan, C. C., Cover, T. L. \& Blaser, M. J. (1997). Analysis of $\mathrm{F}_{1} \mathrm{~F}_{0}$-ATPase from Helicobacter pylori. Infect Immun 65, 2640-2647.

Maddison, W. P. \& Maddison, D. R. (1992). MacClade: Analysis of Phylogeny and Character Evolution. Sunderland, MA: Sinauer.

Maidak, B. L., Cole, J. R., Lilburn, T. G. \& 9 other authors (2000). The RDP (Ribosomal Database Project) continues. Nucleic Acids Res 28, 173-174.

Mickevich, M. F. \& Farris, J.S. (1981). The implications of congruence in Menidia. Syst Zool 30, 351-370.

Moreno, E., Stackebrandt, E., Dorsch, M., Wolters, J., Busch, M. \& Mayer, H. (1990). Brucella abortus $16 \mathrm{~S}$ rRNA and lipid A reveal a phylogenetic relationship with members of the alpha-2 subdivision of the class Proteobacteria. $J$ Bacteriol 172, 3569-3576.

Nick, G., de Lajudie, P., Eardly, B. D., Suomalainen, S., Paulin, L., Zhang, X., Gillis, M. \& Lindström, K. (1999). Sinorhizobium arboris sp. nov. and Sinorhizobium kostiense sp. nov., isolated from leguminous trees in Sudan and Kenya. Int J Syst Bacteriol 49, 1359-1368.

Nour, S. M., Fernandez, M. P., Normand, P. \& Cleyet-Marel, J.-C. (1994). Rhizobium ciceri sp. nov., consisting of strains that nodulate chickpeas (Cicer arietinum L.). Int J Syst Bacteriol 44, 511-522.

Nour, S. M., Cleyet-Marel, J.-C., Normand, P. \& Fernandez, M. P. (1995). Genomic heterogeneity of strains nodulating chickpeas (Cicer arietinum L.) and description of Rhizobium mediterraneum sp. nov. Int J Syst Bacteriol 45, 640-648.

Olsen, G. J., Matsuda, H., Hagstrom, R. \& Overbeek, R. (1994). fastDNAmL: a tool for construction of phylogenetic trees of DNA sequences using maximum likelihood. Comput Appl Biosci 10, 41-48.

Pamilo, P. \& Nei, M. (1988). Relationships between gene trees and species trees. Mol Biol Evol 5, 568-583.

Pueppke, S. G. (1996). The genetic and biochemical basis for nodulation of legumes by rhizobia. Crit Rev Biotechnol 16, $1-51$.

Rome, S., Fernandez, M. P., Brunel, B., Normand, P. \& CleyetMarel, J.-C. (1996). Sinorhizobium medicae sp. nov., isolated from annual Medicago spp. Int J Syst Bacteriol 46, 972-980.

Ronner, S., Liesack, W., Wolters, J. \& Stackebrandt, E. (1991). Cloning and sequencing of a large fragment of the atpD-gene of Pirellula marine: a contribution to the phylogeny of planctomycetales. Endocytobiosis Cell Res 7, 219-229.

Saitou, N. \& Nei, M. (1987). The neighbor-joining method: a new method for reconstructing phylogenetic trees. Mol Biol Evol 4, 406-425.

Sakurada, K., Ohta, T., Fujishiro, K., Hasegawa, M. \& Aisaka, K. (1996). Acetylpolyamine amidohydrolase from Mycoplana ramosa: gene cloning and characterization of the metalsubstituted enzyme. J Bacteriol 178, 5781-5786.

Salminen, M. O., Carr, J. K., Burke, D. S. \& McCutchan, F. E. 
(1995). Identification of breakpoints in intergenotypic recombinants of HIV type 1 by bootscanning. AIDS Res Hum Retroviruses 11, 1423-1425.

Sawada, H., leki, H., Oyaizu, H. \& Matsumoto, S. (1993). Proposal for rejection of Agrobacterium tumefaciens and revised descriptions for the genus Agrobacterium and for Agrobacterium radiobacter and Agrobacterium rhizogenes. Int J Syst Bacteriol 43, 694-702.

Sullivan, J. T., Eardly, B. D., van Berkum, P. \& Ronson, C. W. (1996). Four unnamed species of nonsymbiotic rhizobia isolated from the rhizosphere of Lotus corniculatus. Appl Environ Microbiol 62, 2818-2825.

Swofford, D. L. (1997). Phylogenetic Analysis using Parsimony - PAUP* Sunderland, MA: Sinauer.

Sy, A., Giraud, E., Jourand, P. \& 8 other authors (2001). Methylotrophic Methylobacterium bacteria nodulate and fix nitrogen in symbiosis with legumes. J Bacteriol 183, 214-220.

Thompson, J. D., Gibson, T. J., Plewniak, F., Jeanmougin, F. \& Higgins, D. G. (1997). The CLUSTAL_X windows interface: flexible strategies for multiple sequence alignment aided by quality analysis tools. Nucleic Acids Res 25, 4876-4882.

Thompson, S. A. \& Blaser, M. J. (1995). Isolation of the Helicobacter pylori recA gene and involvement of the recA region in resistance to low pH. Infect Immun 63, 2185-2193.

Turner, S. L. \& Young, J. P. W. (2000). The glutamine synthetases of rhizobia: phylogenetics and evolutionary implications. Mol Biol Evol 17, 309-319.

Tybulewicz, V. L. J., Falk, G. \& Walker, J. E. (1984). Rhodopseudomonas blastica atp operon: nucleotide sequence and transcription. J Mol Biol 179, 185-214.

Wang, E. T., van Berkum, P., Beyene, D., Sui, X. H., Dorado, O., Chen, W. X. \& Martínez-Romero, E. (1998). Rhizobium huautlense sp. nov., a symbiont of Sesbania herbacea that has a close phylogenetic relationship with Rhizobium galegae. Int J Syst Bacteriol 48, 687-699.

Wang, E. T., van Berkum, P., Sui, X. H., Beyene, D., Chen, W. X. \& Martínez-Romero, E. (1999). Diversity of rhizobia associated with Amorpha fruticosa isolated from Chinese soils and description of Mesorhizobium amorphae sp. nov. Int J Syst Bacteriol 49, 51-65.

Weisburg, W. G., Woese, C. R., Dobson, M. E. \& Weiss, E. (1985). A common origin of rickettsiae and certain plant pathogens. Science 230, 556-558.
Weisburg, W. G., Dobson, M. E., Samuel, J. E. \& 7 other authors (1989). Phylogenetic diversity of the rickettsiae. J Bacteriol 171, 4202-4206.

Wheatcroft, R., McRae, D. G. \& Miller, R. W. (1990). Changes in the Rhizobium meliloti genome and the ability to detect supercoiled plasmids during bacteroid development. Mol Plant Microbe Interact 3, 9-17.

White, L. O. (1972). The taxonomy of the crown-gall organism Agrobacterium tumefaciens and its relationship to rhizobia and other agrobacteria. J Gen Microbiol 72, 565-574.

Willems, A. \& Collins, M. D. (1993). Phylogenetic analysis of rhizobia and agrobacteria based on $16 \mathrm{~S}$ rRNA gene sequences. Int J Syst Bacteriol 43, 305-313.

Yanagi, M. \& Yamasato, K. (1993). Phylogenetic analysis of the family Rhizobiaceae and related bacteria by sequencing of $16 \mathrm{~S}$ rRNA gene using PCR and DNA sequencer. FEMS Microbiol Lett 107, 115-120.

Yang, Z., Goldman, N. \& Friday, A. (1994). Comparison of models for nucleotide substitution used in maximum-likelihood phylogenetic estimation. Mol Biol Evol 11, 316-324.

Young, J. M., Kuykendall, L. D., Martínez-Romero, E., Kerr, A. \& Sawada, H. (2001). A revision of Rhizobium Frank 1889, with an emended description of the genus, and the inclusion of all species of Agrobacterium Conn 1942 and Allorhizobium undicola de Lajudie et al. 1998 as new combinations: Rhizobium radiobacter, $R$. rhizogenes, $R$. rubi, $R$. undicola and $R$. vitis. Int $J$ Syst Evol Microbiol 51, 89-103.

Young, J. P. W. (1996). Phylogeny and taxonomy of rhizobia. Plant Soil 186, 45-52.

Young, J. P. W. (1998). Bacterial evolution and the nature of species. In Advances in Molecular Ecology, pp. 119-131. Edited by G. R. Carvalho. Amsterdam: IOS Press.

Young, J. P. W. \& Haukka, K. E. (1996). Diversity and phylogeny of rhizobia. New Phytol 133, 87-94.

Young, J. P. W. \& Johnston, A. W. B. (1989). The evolution of specificity in the legume-rhizobium symbiosis. Trends Ecol Evol 4, 341-349.

Young, J. P. W., Downer, H. L. \& Eardly, B. D. (1991). Phylogeny of the phototrophic rhizobium strain BTAil by polymerase chain reaction-based sequencing of a $16 \mathrm{~S}$ rRNA gene segment. J Bacteriol 173, 2271-2277. 